Polymer Journal, Vol. 3, No. 5, pp 587-590 (1972)

\title{
Thermodynamic Properties of Polyethylene and Eicosane. II. Conformational Entropy of Melting
}

\author{
Yoshiharu Tsujita, Takuhei Nose, and Toshio Hata \\ Department of Polymer Technology, Tokyo Institute of Technology, \\ Ookayama 2-12-1, Meguro-ku, Tokyo, Japan.
}

(Received December 22, 1971)

\begin{abstract}
The entropy of melting $\Delta S_{\mathrm{m}}$ is divided into three parts according to Starkweather and Boyd: the entropy change due to disordering of molecular arrangements $\Delta S_{\mathrm{dis}}$ at constant volume, the change of chain conformations $\Delta S_{\mathrm{c}}$ and the entropy arising from the change of volume $\Delta S_{\mathrm{v}} . \Delta S_{\mathrm{V}}$ was evaluated from the experimental results on the $P-V-T$ relations for linear polyethylene and eicosane, where the volume dependence of the value of $(\partial S / \partial V)_{T}=(\partial P / \partial T)_{V}$ is taken into consideration. $\Delta S_{\text {dis }}$ was estimated with the aid of the thermodynamic data for simple spherical molecules such as $\mathrm{Ar}$ and $\mathrm{CCl}_{4}$. As results the conformational entropy of melting $\Delta S_{\mathrm{c}}$ was obtained as $1.51 \mathrm{cal} / \mathrm{CH}_{2} \mathrm{~mol} \mathrm{deg}$ for polyethylene and $1.94 \mathrm{cal} / \mathrm{CH}_{2} \mathrm{~mol} \mathrm{deg}$ for eicosane, which are in good agreement with the theoretical predictions of several authors.

KEY WORDS Polyethylene / Eicosane / Entropy of Melting / $P$ $V-T$ Relations / Conformational Entropy / Disordering Entropy / Clausius-Clapeyron Equation /
\end{abstract}

Melting phenomena of crystalline polymers differ from those of low-molecular-weight substances in various ways. The most characteristic aspect of polymer melting is considered to be in the fact that change of chain conformation occurs on melting and may play an important role in the entropy of melting, besides the change of volume and molecular orderliness as in low molecular weight crystals. Therefore it would be fruitful to distinguish these effects on the entropy of melting, and to discuss them separately.

Mandelkern ${ }^{1}$ firstly proposed dividing the entropy of melting $\Delta S_{\mathrm{m}}$ into two parts, the one at constant volume $\left(\Delta S_{\mathrm{m}}\right)_{V}$ and the other due to the volume change $\Delta S_{\nabla}$. Succeedingly Starkweather and Boyd $^{2}$ tried to divide $\left(\Delta S_{\mathrm{m}}\right)_{V}$ into a further two parts, the entropy change due to the change of molecular arrangements from order to disorder (the disordering entropy $\Delta S_{\mathrm{dis}}$ ) and the one due to the change of chain conformations on melting (the conformational entropy $\left.\Delta S_{\mathrm{c}}\right)$, that is,

$$
\begin{aligned}
\Delta S_{\mathrm{m}} & =\left(\Delta S_{\mathrm{m}}\right)_{V}+\Delta S_{\mathrm{v}} \\
& =\left(\Delta S_{\mathrm{dis}}+\Delta S_{\mathrm{c}}\right)+\Delta S_{\mathrm{v}}
\end{aligned}
$$

In this paper an attempt is made to estimate these three terms of the entropy of melting on the basis of the experimental results for the pressure-volume-temperature $(P-V-T)$ relations of linear polyethylene and eicosane, using a different method to that of Starkweather and Boyd.

\section{EXPERIMENTAL}

The sample used in this study were a linear polyethylene (unfractionated Hizex $\bar{M}=34000$ ) presented by Mitsui Petroleum Co. and eicosane (99.9-\% purity). The apparatus was the same as in the preceding paper. ${ }^{3}$ Quantities needed for the discussion, i.e., the volume change on melting $\Delta V_{\mathrm{m}}$, the pressure dependence of the melting temperature $\mathrm{d} T_{\mathrm{m}} / \mathrm{d} P$ and the dependence of thermal pressure coefficient on volume, were obtained from the $P-V-T$ relations. In order to determine the value of $\mathrm{d} T_{\mathrm{m}} / \mathrm{d} P$, the measurements of the $P-V-T$ relationship were made in the vicinity of the melting temperatures, that is, $V-T$ measurements at constant pressures. The heating rate was kept carefully $0.3^{\circ} \mathrm{C} / \mathrm{min}$ for each pressure. The values of $\mathrm{d} T_{\mathrm{m}} / \mathrm{d} P$ were $0.0276^{\circ} \mathrm{C} / \mathrm{kg} \mathrm{cm}^{2}$ for polyethylene and $0.0214^{\circ} \mathrm{C} /$ $\mathrm{kg} \mathrm{cm}{ }^{2}$ for eicosane at atmospheric pressure. 


\section{ESTIMATIONS OF ENTROPY OF MELTING AND ITS COMPONENTS}

One can obtain the entropy of melting from the thermodynamic quantities. As shown in the following, $\Delta S_{\mathrm{v}}$ was derived first and $\left(\Delta S_{\mathrm{m}}\right)_{V}$ necessarily obtained from eq 1 . Next $\Delta S_{\text {dis }}$ was estimated, and $\Delta S_{\mathrm{c}}$ then evaluated as $\left(\Delta S_{\mathrm{m}}\right)_{V}-\Delta S_{\mathrm{dis}}$.

\section{Entropy of Melting}

With the use of the values of $\mathrm{d} T_{\mathrm{m}} / \mathrm{d} P$ above obtained, the entropy of melting was calculated by the Clausius-Clapeyron equation

$$
\frac{\mathrm{d} T_{\mathrm{m}}}{\mathrm{d} \boldsymbol{P}}=\frac{\Delta V_{\mathrm{m}}}{\Delta S_{\mathrm{m}}}
$$

where $\Delta V_{\mathrm{m}}$ is the volume change on melting and $\Delta S_{\mathrm{m}}$ is the entropy of melting. $\Delta V_{\mathrm{m}}$ was obtained by the extrapolation of volume in the temperature region below that in which the premelting occurs, to that at the melting temperature. The value of $\Delta V_{\mathrm{m}}$ for polyethylene of $100-\%$ crystallinity was calculated by dividing the observed value with its crystallinity of 0.782 . The observed value of eicosane was considered to be that for $100-\%$ crystallinity. $\Delta S_{\mathrm{m}}$ thus obtained by eq 3 were $2.53 \mathrm{cal} / \mathrm{CH}_{2} \mathrm{~mol} \mathrm{deg}$ for polyethylene and $3.50 \mathrm{cal} / \mathrm{CH}_{2} \mathrm{~mol} \mathrm{deg}$ for eicosane.

\section{The Entropy Change due to the Volume Change} $\Delta S_{\mathrm{v}}$

$\Delta S_{\nabla}$ can be evaluated with the use of the Maxwell's relation $(\partial S / \partial V)_{T}=(\partial P / \partial T)_{V}$, as

$$
\Delta S_{\mathrm{V}}=\int\left(\frac{\partial P}{\partial T}\right)_{V} \mathrm{~d} V
$$

Thermal pressure coefficient $(\partial \boldsymbol{P} / \partial T)_{V}=\gamma$ varies with volume as shown in Figure 1 for instance in the liquid state. It is more reasonable to take into consideration this dependence of $\gamma$ on volume in the calculation. As was discussed in the previous paper, internal pressure $P_{\mathrm{i}}$, which is approximately equal to $T_{\gamma}$, increases continuously as volume decreases in the liquid state. Therefore $\gamma$ may also increases with volume decreasing, although the volume dependence of $\gamma$ is not exactly estimated for the wide range of volume. Hence we assume here that $\gamma$ increases as volume decreases with the same slope

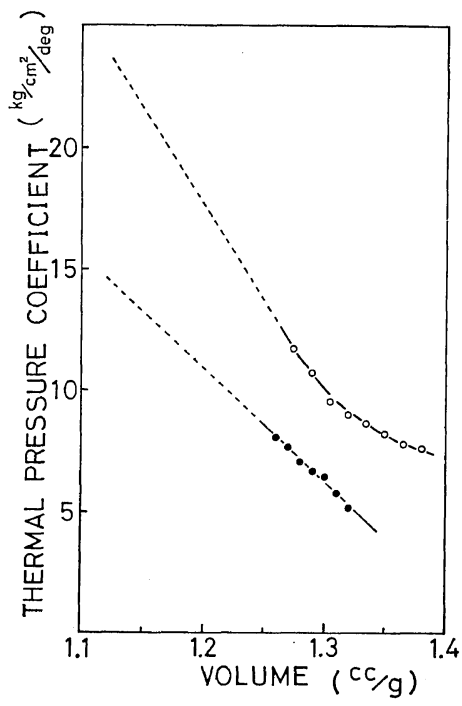

Figure 1. Relation between thermal pressure coefficient and specific volume: $\bigcirc, \mathrm{PE} ; \bigcirc$, eicosane.

of $\gamma$ vs. $V$ curve as that in the vicinity of the melting point in the liquid state, as shown by the dotted lines in Figure 1. Values of $\Delta S_{\mathrm{V}}$ thus obtained are $0.91 \mathrm{cal} / \mathrm{CH}_{2} \mathrm{~mol} \mathrm{deg}$ for polyethylene and $1.44 \mathrm{cal} / \mathrm{CH}_{2} \mathrm{~mol} \mathrm{deg}$ for eicosane.

\section{The Disordering Entropy $\Delta S_{\mathrm{dis}}$}

If one considers a simple spherical molecule of low molecular weight, it has no intramolecular freedom, therefore $\Delta S_{\mathrm{c}}$ is equal to zero. In this case one can write eq 1 and 2 as

$$
\Delta S_{\mathrm{dis}}=\left(\Delta S_{\mathrm{m}}\right)_{V}=\Delta S_{\mathrm{m}}-\Delta S_{\mathrm{V}}
$$

$\operatorname{Argon}(\mathrm{Ar})$ and carbon tetrachloride $\left(\mathrm{CCl}_{4}\right)$ were chosen as such typical molecules. $\Delta S_{\mathrm{m}}$ and $\Delta S_{V}=\int(\partial P / \partial T)_{V} \mathrm{~d} V$ were calculated in the same manner as above described, by the use of necessary data from Bridgman's paper ${ }^{5}$ and the Critical Table. $^{6} \quad \Delta S_{\text {dis }}$ thus obtained were 0.94 $\mathrm{cal} / \mathrm{mol} \mathrm{deg}$ for $\mathrm{Ar}$ and $0.97 \mathrm{cal} / \mathrm{mol} \mathrm{deg}$ for $\mathrm{CCl}_{4}$ which are surprisingly close to each other. In Table $I$ the thermodynamic quantities used are summarized.

If one can assume that this disordering entropy of melting per mole is independent of substances including polymers, one can calculate $\Delta S_{\mathrm{c}}$, using the mean value of $\Delta S_{\mathrm{dis}}, 0.95 \mathrm{cal} / \mathrm{mol} \mathrm{deg}$. However, in the case of polymeric substances there 
Table I. Thermodynamic quantities on melting of $\mathrm{Ar}$ and $\mathrm{CCl}_{4}$

\begin{tabular}{lll}
\hline & $\mathrm{Ar}$ & $\mathrm{CCl}_{4}$ \\
\hline $\mathrm{d} T_{\mathrm{m}} / \mathrm{d} P, \mathrm{deg} / \mathrm{kg} \mathrm{cm}{ }^{2}$ & 0.0238 & 0.0393 \\
$\Delta V_{\mathrm{m}}, \mathrm{cc} / \mathrm{g}$ & 0.0795 & 0.0258 \\
$\Delta S_{\mathrm{m}}, \mathrm{cal} / \mathrm{mol} \mathrm{deg}$ & 3.13 & 2.37 \\
$\Delta S_{\mathrm{\vee}}$ & 2.19 & 1.40 \\
$\left(\Delta S_{\mathrm{m}}\right) V$ & 0.94 & 0.97 \\
\hline
\end{tabular}

is a further problem of how to choose the mole unit. This unit is considered to be the one which has three external degrees of freedom. If one accepts the corresponding state theorem recently developed for polymer liquids, one can determine the size of such a unit. According to $\mathrm{Nose}^{7}$ this unit has about nine $-\mathrm{CH}_{2}-$ groups for polyethylene and about eight for eicosane. Thus $\Delta S_{\text {dis }}$ must be $0.11 \mathrm{cal} / \mathrm{CH}_{2} \mathrm{~mol} \mathrm{deg}$ for polyethylene and $0.12 \mathrm{cal} / \mathrm{CH}_{2} \mathrm{~mol} \mathrm{deg}$ for eicosane.

\section{The Conformational Entropy $\Delta S_{\mathrm{c}}$}

By subtracting $\Delta S_{\mathrm{dis}}$ from $\left(\Delta S_{\mathrm{m}}\right)_{V}$ one obtains the values of $\Delta S_{\mathrm{c}}$ as $1.51 \mathrm{cal} / \mathrm{CH}_{2} \mathrm{~mol} \mathrm{deg}$ for polyethylene and $1.94 \mathrm{cal} / \mathrm{CH}_{2} \mathrm{~mol} \mathrm{deg}$ for eicosane.

Values of various entropies estimated above are tabulated in Table II including thermodynamic quantities on melting.

Table II. Thermodynamic quantities on melting of eicosane and polyethylene

\begin{tabular}{lcc}
\hline & Eicosane & Polyethylene \\
\hline$T_{\mathrm{m}},{ }^{\circ} \mathrm{C}$ & 39.3 & 134.0 \\
Crystallinity, \% & & 78.2 \\
$\mathrm{~d} T_{\mathrm{m}} / \mathrm{d} P, \mathrm{deg} / \mathrm{kg} \mathrm{cm}{ }^{2}$ & 0.0214 & 0.0276 \\
$\Delta V_{\mathrm{m}}, \mathrm{cc} / \mathrm{g}$ & 0.228 & 0.213 \\
$\Delta S_{\mathrm{m}}, \mathrm{cal} / \mathrm{CH}_{2} \mathrm{~mol} \mathrm{deg}$ & 3.50 & 2.53 \\
$\Delta H_{\mathrm{m}}, \mathrm{cal} / \mathrm{CH}_{2} \mathrm{~mol}$ & 1094 & 1030 \\
$\Delta S_{\mathrm{\vee}}, \mathrm{cal} / \mathrm{CH}_{2} \mathrm{~mol} \mathrm{deg}$ & 1.44 & 0.91 \\
$\left(\Delta S_{\mathrm{m}}\right) V$ & 2.06 & 1.62 \\
$\Delta S_{\mathrm{dis}}$ & 0.12 & 0.11 \\
$\Delta S_{\mathrm{c}}$ & 1.94 & 1.51 \\
\hline
\end{tabular}

\section{DISCUSSION}

The estimation made by Starkweather, et al., differs from this in the estimation method. Starkweather, et al., first calculated $\Delta S_{\mathrm{c}}$ theo- retically and then obtained $\Delta S_{\mathrm{dis}}$. On the contrary in this study $\Delta S_{\mathrm{dis}}$ was first estimated using various assumptions and then $\Delta S_{\mathrm{c}}$ obtained.

In the evaluation of $\Delta S_{\mathrm{v}}$, Starkweather and other authors assumed a constant value for the thermal pressure coefficient $\gamma=(\partial P / \partial T)_{V}$. If the same assumption is made, $\Delta S_{\mathrm{v}}$ is given as 0.54 $\mathrm{cal} / \mathrm{CH}_{2}$ mol deg with the use of the authors' data for polyethylene which agrees with the values of Starkweather, et al., ${ }^{2}$ and Quinn, et $a l .^{3}$ However taking into consideration of the dependence of $\gamma$ on volume, $\Delta S_{\nabla}$ was evaluated as $0.91 \mathrm{cal} / \mathrm{CH}_{2} \mathrm{~mol} \mathrm{deg}$ for polyethylene and $1.44 \mathrm{cal} / \mathrm{CH}_{2} \mathrm{~mol} \mathrm{deg}$ for eicosane. In comparison of this result with the value of Starkweather, et al., their value for polyethylene is as small as $62 \%$ of this. Starkweather and Boyd have calculated $\Delta S_{\mathrm{c}}$ with the use of the partition function of Flory, ${ }^{8}$ in which the energy difference between trans and gauche conformations is taken into consideration, to obtain $\Delta S_{\mathrm{c}}=1.59$ $1.70 \mathrm{cal} / \mathrm{CH}_{2} \mathrm{~mol} \mathrm{deg}$ for polyethylene. Kirschenbaum $^{9}$ has also evaluated the change in conformational entropy of fusion by considering the rotational isomers and pentane effect and obtained the value of $1.8 \mathrm{cal} / \mathrm{CH}_{2} \mathrm{~mol} \mathrm{deg}$. Smith $^{10}$ calculated the configurational entropy of a single chain, considering the disallowance of gauche-gauche prime or its inverse conformation, and gave the value of $1.59-1.68 \mathrm{cal} /$ $\mathrm{CH}_{2}$ mol deg. These values calculated by several authors are fairly in good agreements with the authors' experimental results and this seems to confirm the validity of their treatment for $\Delta S_{\mathrm{dis}}$.

Introducing Broadhurst's empirical equation, which relates the melting temperature of $n$ hydrocarbon to the number of carbon atoms, to Smith's equation, one obtains the dependency of the configurational entropy of a single chain on molecular weight, from which it is concluded that the conformational entropy of eicosane must be larger than that of polyethylene. It coincides with the results of this study.

\section{REFERENCES}

1. L. Mandelkern, "Crystallization of Polymers," McGraw-Hill Book Co., New York N.Y., 1964.

2. H. W. Starkweather and R. H. Boyd, J. Phys. Chem., 64, 410 (1960). 
3. Y. Tsujita, T. Nose, and, T. Hata, the first paper of this series, to be published in Polymer $J$. .

4. F. A. Quinn Jr. and L. Mandelkern, J. Amer. Chem. Soc., 80, 3178 (1958).

5. P. W. Bridgman, Phys. Rev., 3, 126 and 133 (1914); ibid., 6, 1 and 94 (1915).

6. E.W. Washburn, "International Critical Tables," Vol 3, McGraw-Hill Book Co., New
York, N.Y., 1928.

7. T. Nose, Polymer J., 2, 124 (1971); ibid., 3, 1 (1972).

8. P. J. Flory, Proc. Roy. Soc., (London) 234A, 60 (1956).

9. I. Kirshenbaum, J. Polym. Sci., Part A, 3, 1869 (1965).

10. R. P. Smith, ibid., Part A-2, 4, 869 (1966). 